\title{
Hydrogen Generation from Biowaste \& its Application as a Fuel
}

\author{
Roopali Patil ${ }^{1}$, Shraddha Vinchurkar ${ }^{1}$, Pallavi Jadhav ${ }^{1}$, Joydeep Sarkar ${ }^{1}$, M. Sharmila ${ }^{1}$ \\ Assistant Professor, Department of Electrical Engineering, Sandip Institute of Engineering \& Management, \\ Nashik, Maharashtra, India ${ }^{1}$
}

\begin{abstract}
With gradual decrease in our conventional energy resources and the grave threat of global warming, there is a need to find sources that are long lasting. Hydrogen as fuel provides a very good option. Hydrogen production uses Natural gas and electrolysis of water, thus directly or indirectly creating pollution. As per this, we cannot say Hydrogen as a clean energy. So, we need to categorize clean Hydrogen production techniques. In this review paper, we will brief the biological methods of Hydrogen production from biomass. Also, we will look into direct hydrogen applications.
\end{abstract}

Keywords: Biological $\mathrm{H}_{2}$ production, Aerobic Reaction, Anaerobic reactions, Fuel cell.

\section{INTRODUCTION}

Energy is the need for every generation. Any applications, thus having a high chance of becoming an technological advancement is supported by continuity of economically feasible technology.

power. With gradual depletion of conventional resources, the world is looking towards clean and green energy sources to satisfy the demand of the present generation. The scientific world is providing us with solutions but their use is restricted due to lack of funds or technology. In this scenario, Fuel Cells possess the potential for its use on large scale. Fuel Cells are now being introduced commercially for large scale domestic use, revolutionizing the way we produce power. Presently Fuel Cells uses Hydrogen as fuel, offering us a clean sustainable power source, with water as byproduct. Hydrogen Fuel Cell is seen as a possible replacement for conventional power production in many applications, especially on-site/off-grid power production.

But the problem with hydrogen is that it is an inert gas, and extracting \& packing hydrogen for usage is a difficult \& costly process. In majority, Hydrogen is produced from natural gas and its production is accompanied by $\mathrm{CO}_{2}$ emission, which is a greenhouse gas. Also, hydrogen production by electrolysis consumes large amount of power which indirectly comes from conventional power plants. So newer methods of $\mathrm{H}_{2}$ production are being worked on with, which reduces the emissions caused in conventional methods.

\section{BIOLOGICAL HYDROGEN GENERATION}

Hydrogen is considered as a clean fuel because on combustion it generates water. So, basically Hydrogen is renewable, as it can be reformed from by-products. [1] It has high a very high energy content per unit mass. Presently, only $40 \%$ of hydrogen is produced from natural gas, $30 \%$ from heavy oils and naphtha, $18 \%$ from coal, and $4 \%$ from electrolysis and about $1 \%$ is produced from biomass.[2] The methods used today uses Natural gas as input, thus producing $\mathrm{CO}_{2}$ and other waste gases.

Electrolysis of water looks like a clean method but the electrical power required to drive electrolysis process comes from thermal or nuclear power plants, that is indirectly creating pollution. In coal gasification process, large amount of waste gases are produced containing sulphur compounds, thus highly polluting. [3] To meet the emission levels of $\mathrm{CO}_{2}$ as imposed by the Kyoto protocol, hydrogen should be produced from renewable energy sources. [4] Indirect hydrogen production by electrolysis using electricity from renewable resources, such as sunlight, wind and hydropower, is also possible to incorporate the tag of pollution free hydrogen generation.

Biological methods of $\mathrm{H}_{2}$ production by the action of microbes on wastewater and biomass wastes is very important as it consumes waste helping the reduction of garbage volume, it can be applied on wastewater which results in wastewater treatment and the process is free of greenhouse gas emissions. Biological hydrogen production delivers clean hydrogen with an environmental-friendly technology and is very suitable for the conversion of wet biomass in small-scale

Hydrogen is a natural, though transient, by-product of several microbial driven biochemical reactions, mainly in anaerobic fermentation processes. In addition, certain microorganisms can produce enzymes that can produce $\mathrm{H}_{2}$ from water if an outside energy source, like sunlight, is provided to them. Many microorganisms are able to produce hydrogen from monosaccharides and disaccharides, starch and hemicellulose under anaerobic conditions. The anaerobic production of hydrogen is a common 


\section{ISO 3297:2007 Certified}

Vol. 5, Issue 3, March 2017

phenomenon, occurring during the process of anaerobic digestion.

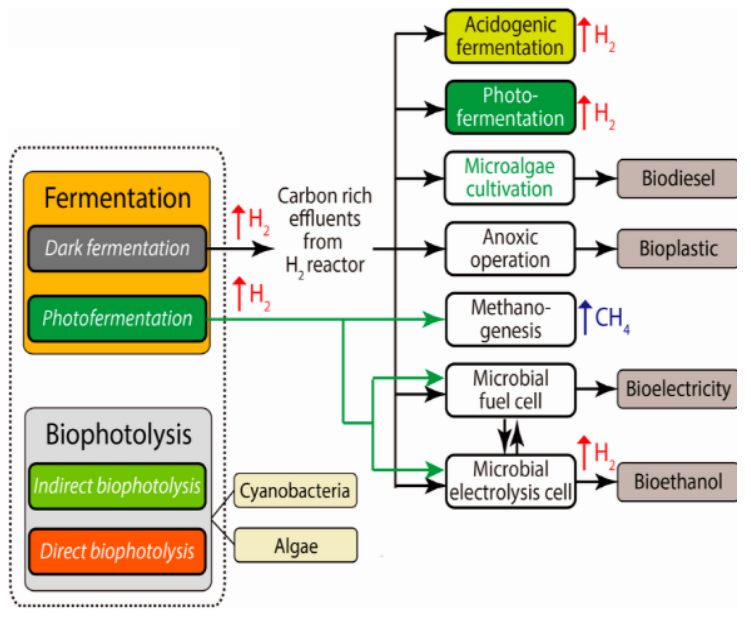

Fig 1 - Hydrogen Production Methods

Here, hydrogen producing microorganisms are in syntrophy with methanogenic bacteria which consume the hydrogen as soon as it is produced. In this way, hydrogen production remains obscure and methane is the end-product. By uncoupling $\mathrm{H}_{2}$ production from methane production, $\mathrm{H}_{2}$ becomes available for recovery and exploitation.

The selection of extreme thermophilic bacteria is due to its higher hydrogen production efficiency as compared to mesophilic bacteria, for the production of hydrogen from renewable resources. For this purpose the feedstock can range from crop wastes of high sugar content and waste streams of domestic organic waste, paper sludge and potato steam peels etc.

Hydrogen production can be achieved by certain microbes like Caldicellulosiruptor saccharolyticus, Thermotoga elfiiand Thermotoganeapolitanaare observed in various research experiments. [5] Nutrient requirements and inhibitory effects differed depending on the strain and the feedstock applied. Specific ways in which microbes can produce $\mathrm{H}_{2}$ are described below:

- Biophotolysis of water using green \& blue-green algae (cyanobacteria)

o Direct biophotolysis

o Indirect bio-photolysis

- Photo-fermentation

- Dark fermentation

- Hybrid systems

o Using dark fermentative and Photo-fermentative bioreactors

o Bio-electrochemically assisted microbial bioreactors.
A. Direct Biophotolysis

A direct biophotolysis of $\mathrm{H}_{2}$ production is a biological process which utilizes solar energy and photosynthetic systems of algae to convert water into chemical energy. [6]

$$
2 \mathrm{H}_{2} \mathrm{O}+\text { solar energy } \rightarrow 2 \mathrm{H}_{2}+\mathrm{O}_{2}
$$

The two photosynthetic systems (PS) responsible for photosynthesis process are:

1. Photosystem I (PS I)

This produces reductant for $\mathrm{CO}_{2}$.

2. Photosystem II (PS II)

This splits water to evolve $\mathrm{O}_{2}$.

In the above process, two protons $\left(\mathrm{H}^{+}\right)$are released. In the presence of 'Hydrogenase' enzyme, these two protons can produce one molecule of $\mathrm{H}_{2}$. Hydrogenase enzyme is present in green algae and cyanobacteria, thus they possess the ability of generating hydrogen.[7]

$$
\mathrm{H}_{2} \mathrm{O} \rightarrow \text { PSII } \rightarrow \text { PSI } \rightarrow \text { Fd } \underset{\downarrow}{\rightarrow} \text { Hydrogenase } \rightarrow \mathrm{H}_{2}
$$

Since hydrogenase is sensitive to oxygen, it is necessary to maintain the oxygen content at a low level (under $0.1 \%$ ) so that the hydrogen production can be sustained. This condition can be obtained by the use of green algae, Chlamydomonasreinhardtii, which can deplete oxygen during the oxidative respiration. However, the reaction is very short-lived and the rate of the hydrogen production is very low, less than one-tenth than that of other photosynthetic reactions.[8]

\section{B) Indirect Bio-photolysis}

In indirect bio-photolysis, the problem of sensitivity of the $\mathrm{H}_{2}$ evolving process to $\mathrm{O}_{2}$ is usually circumvented by separating $\mathrm{O}_{2}$ and $\mathrm{H}_{2}$. In this process, $\mathrm{CO}_{2}$ is intermittently fixed and released serving as the electron carrier between the $\mathrm{O}_{2}$ producing (water splitting) reaction and the $\mathrm{O}_{2}$ sensitive hydrogenase reactions.

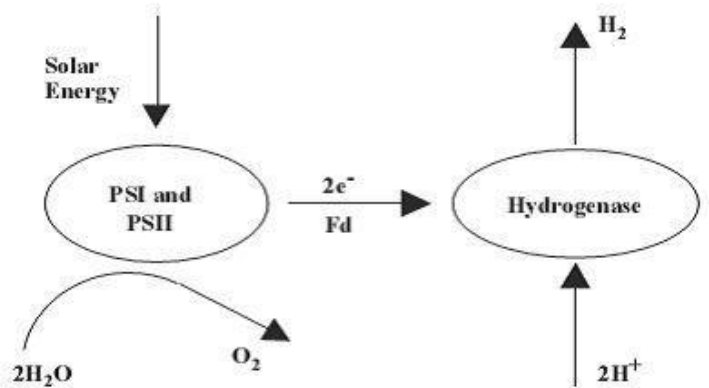

Fig 2- Direct Biophotolysis

In such concepts the algae undergo a cycle of $\mathrm{CO}_{2}$ fixation into storage carbohydrates (starch, glycogen) followed by its conversion to $\mathrm{H}_{2}$ by dark anaerobic fermentation processes. In a typical indirect bio-photolysis $\mathrm{H}_{2}$ is produced as follows: [9] 


\section{ISO 3297:2007 Certified}

Vol. 5, Issue 3, March 2017

\section{C) Photo-fermentation}

$\mathrm{H}_{2}$ production by purple non-sulphur bacteria is mainly due to the presence of nitrogenase under oxygendeficient conditions using light energy and reduced compounds (organic acids). The reaction is as follows:

$$
\mathrm{C}_{6} \mathrm{H}_{12} \mathrm{O}_{6}+12 \mathrm{H}_{2} \mathrm{O}+\text { Light energy } \rightarrow 12 \mathrm{H}_{2}+6 \mathrm{CO}_{2}
$$

The overall biochemical pathways for the photofermentation process can be expressed as follows:

$$
\begin{gathered}
\left(\mathrm{CH}_{2} \mathrm{O}\right)_{2} \rightarrow(\mathrm{NADPH}) \\
\uparrow \text { ATP }
\end{gathered}
$$

Many types of green algae and cyanobacteria, besides having the ability to fix $\mathrm{CO}_{2}$ via photosynthesis, also have the ability to fix nitrogen from the atmosphere and produce enzymes that can catalyse the second $\mathrm{H}_{2}$ generating step. Since these nitrogen fixing enzymes, nitrogenase, are localized within the heterocyst, they provide an $\mathrm{O}_{2}$ free environment to carry out the $\mathrm{H}_{2}$ evolution reactions. [10]The advantage of this method is in the versatile metabolic capabilities of these organisms and the lack of Photosystem II (PSII), which automatically eliminates the difficulties associated with $\mathrm{O}_{2}$ inhibition of $\mathrm{H}_{2}$ production. Major bottlenecks of the process involve low photochemical efficiencies (3-10 $\%)$. Moreover, inhomogeneity of the light distribution in the reactor also contributes to lowering of the overall light conversion efficiency.

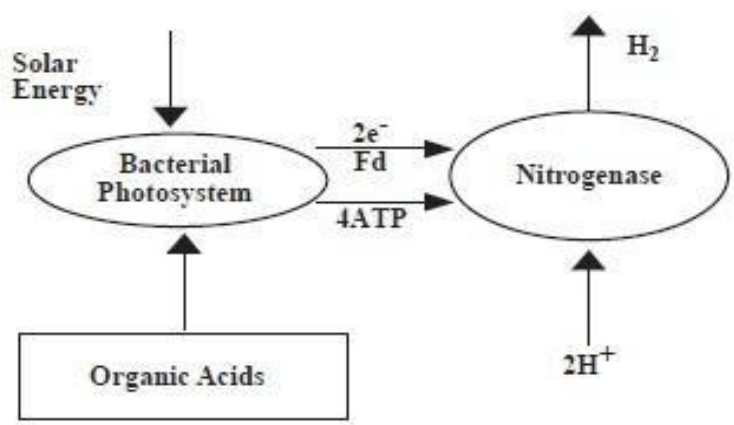

Fig 3- Photo-fermentation

\section{APPLICATION OF HYDROGEN}

Hydrogen is an ideal replacement for fossil fuels in furnaces, internal combustion engines, turbines and jet engines. Present pressure on environment are concentrating hydrogen research and development efforts on hydrogen as an alternative fuel to power our mobility and transportation needs. In electrified vehicles, for example, it is used to run fuel cells which convert hydrogen efficiently to electricity.

The application spectrum of fuel cells is vast. They have the potential to replace conventional power generators such as combustion engines or even large batteries in cars, buses; forklift trucks (FLTs), submarines, and backup and power plants.

A) Hydrogen Fuel Cell

Hydrogen Fuel Cell are devices which provides zero emission and run on compressed hydrogen fed into a fuel cell "stack" that produces electricity to power the vehicle. A fuel cell can be used in combination with an electric motor to drive a vehicle. A hydrogen fuel cell electric vehicle is powered a fuel cell stack. The stack is designed to contain enough cells to provide the necessary power for the automotive application. A fuel cell stack produces power as long as fuel is available, similar to a combustion engine. The electricity generated by the fuel cell stack powers the electric motor that propels the vehicle. Each fuel cell is an anode, a cathode and a proton exchange membrane sandwiched in between. Hydrogen, from a tank on-board the vehicle, enters into the anode side of the fuel cell. Oxygen, pulled from the air, enters the cathode side. As the hydrogen molecule encounters the membrane, a catalyst forces it to split into electron and proton. The proton moves through the fuel cell stack and the electron follows an external circuit, delivering current to the electric motor and other vehicle components. At the cathode side, the proton and electron join again, and then combine with oxygen to form the vehicle's only tailpipe emission, water.

\section{B) Application as Liquid Hydrogen}

Liquid hydrogen proved to be one of the most significant technical accomplishments. Its light and extremely powerful rocket propellant as it has the lowest molecular weight of any known substance and burns with extreme intensity $\left(5,500^{\circ} \mathrm{F}\right)$. In combination with an oxidizer such as liquid oxygen, liquid hydrogen yields the highest specific impulse, or efficiency in relation to the amount of propellant consumed, of any known rocket propellant.

\section{CONCLUSION}

In this study we have seen that there are many processes are available that can be used to generate hydrogen by completely organic process based on microbial activities. The direct result of these methods the utilisation of organic wastes and water as raw material. Adaptation of these technique can ensure a completely renewable hydrogen generation. The alternate use of the process could be made in waste disposal methods, where the microbes can be used to work on organic waste to generate hydrogen.

\section{REFERENCES}

[1] Committee on Alternatives and Strategies for Future Hydrogen Production and Use, National Research Council. The Hydrogen Economy: Opportunities, Costs, Barriers, and R\&D Needs Washington, D.C.: The National Academy Press. 2004

[2] Dougherty W, Kartha S, Rajan C, Lazarus M, Bailie A, Runkle B, Fencl A., "Greenhouse gas reduction benefits and costs of a largescale transition to hydrogen in the USA". Energy Policy (2008) 
[3] Ronald W. Breault, "Gasification Processes Old and New: A Basic Review of the Major Technologies", Energies, Vol 3, 2010

[4] Gregorio Marbán, Teresa Valdés, "Towards The Hydrogen Economy?", SolísInstitutoNacional del Carbón (CSIC), Spain, Int. J. Hydrogen Energy (2007)

[5] S S. Pawar, V Nkemka, Ahmad A. Zeidan, M. Murto, "Biohydrogen production from wheat straw hydrolysate Caldicellulosiruptor saccharolyticus followed by biogas production in a two-step uncoupled process", Intr. Journal of Hydrogen Energy, Volume 38, Issue 22, 2013

[6] A Frock, Jaspreet S. N, and Robert M. Kelly. "The Genus Thermotoga: Recent Developments." Environmental technology, 2010

[7] J.Yu, P.Takahashi, "Biophotolysis-based Hydrogen Production by Cyanobacteria and Green Microalgae", Communicating Current Research and Educational Topics and Trends in Applied Microbiology, 2007

[8] P.C.Hallenbeck, J.R.Benemann, "Biohydrogen - The Microbiological Production of Hydrogen Fuel", Biotechnology Vol.7, Encyclopedia of Life Support Systems (EOLSS)

[9] EnginGürtekin, "Biological Hydrogen Production Methods", Department of Environmental Engineering Firat University, Turkey, Akademic Platform, 2014.

[10] Holladay JD, Hu J, King DL, Wang Y. An overview of hydrogen production technologies. Catal. Today. 2009 